\title{
Oral Literacies: When Adults Read Aloud
}

\section{Sam Duncan}

Routledge, 2021, pp. 212

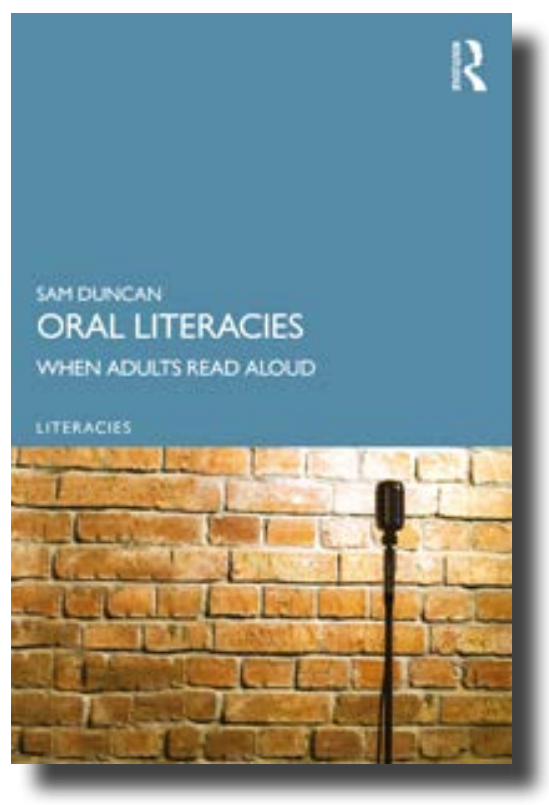

\section{Reviewed by Jamie D. I. Duncan} Lancaster University

$\mathrm{T}$ This book is rare in that it focusses on an area of literacy studies that at first glance seems familiar, but which in fact has been remarkably under researched. Addressing this gap was thus one of the starting points of Oral Literacies: When Adults Read Aloud, according to its author, Sam Duncan, an adult education specialist, and literacy across the lifespan researcher, at University College London.

Over the last ten years, Duncan has published in adult reading development, reading for pleasure, and community reading circles, both in the UK and elsewhere. Along the way, she encountered the need for a book which theorized adult reading aloud as a part of people's everyday lives. Not finding one, the book Oral Literacies came into being with its broad scope and nuanced approach to adult reading aloud practices. Owing to these, this is a book which will interest a wide range of researchers, graduate students, and teaching practitioners, across the field of community writing.

So what exactly are oral literacies? How would one go about researching such a topic? And, indeed, how might this new term help us to understand contemporary literacy practices? Prior to answering these questions through an overview of the book, it is worth pointing out the period in which it was published-that is, one year into the global COVID-19 pandemic. Regarding this moment, Duncan states: "some of the ideas within the book became more obvious or acute in the new world of 'lockdown', [where] the powers of the voice and ear seemed particularly important as ways to be together while not together" (xi).

This latter sentiment perhaps makes sense to the many people who necessarily engaged in digitally mediated relationships, increasingly so, throughout the pandemic, and Duncan lists examples of online reading aloud and listening to reading which gained in prominence. Yet, long prior to lockdown, of course, both online, and offline, reading aloud has played many important roles across a wide range of personal, familial, educational, professional, leisure, cultural, political, and also religious interactions. Oral Literacies discusses reading aloud practices relating to each of these domains in detail. 
Chapter one starts by describing what is referred to as the dominant view of adult reading in Anglophone and Western European settings-where contemporarily reading is most associated, societally, with being a silent, individual, and comprehension-focused activity. This idea then gets deconstructed and the argument of the book is forwarded, concerning how the dominant viewpoint does not depict the reading practices of adults holistically, what they actually do, and why-particularly, in relation to oral reading (or reading aloud) and aural aspects of listening to reading.

A literature review then follows, revolving around five main fields of research on reading: formal education, family studies, ethnography, literature, and history. Regarding the first two, Duncan highlights the breadth of work there has been on reading aloud, but how this centers mostly on children and a limited range of settings in which reading gets done. Relating to the next three, Duncan overviews situated and multimodal accounts of reading, as well as historical studies which challenge teleological accounts of a transition from reading aloud towards silent reading, as if one replaced the other. Hence, Duncan states two aims of the book as; first, "to challenge this dominant discourse of silent, individual adult reading and indeed to challenge the idea that oral reading is itself 'one thing"'; then secondly, to do this by examining as wide a range as possible of contemporary reading aloud practices which "adults perform or experience in the different contexts, communities, languages and phases of their lives" (4).

Chapter two details Reading Aloud in Britain Today (RABiT), a two-year funded study from 2017-2019, concerning, in short, how, what, and why adults read aloud and listen to others doing so. Duncan's book resulted from the RABiT project and its three main forms of data collection: a national questionnaire; a citizen commentary project; and interviews carried out across the UK. Chapter three outlines the design and data of the questionnaire. Across extensive examples readers get an initial the sense of, as Duncan puts it, how adult "reading aloud practices are ubiquitous and remarkably varied", and "important to personal or cultural identities" (47). An initial typology of reading aloud practices is also developed in chapter three, including multiple perspectives on their 'commonness' - from the socially pervasive to the hidden or invisible.

One of Duncan's most distinctive features in RABiT is the incorporation of a unique citizen commentary project called the Mass Observation Archive (MOA). The MOA emerged in the UK in the 1930s, where, in brief, realizing that the mainstream press at the time did not know what 'the masses' thought about contemporary issues, a group of social scientists, media producers, and artists, came together to start a part research project and part political movement, where among other activities, volunteers started to write about what they did and thought about particular topics. The MOA still continues today, basically functioning through a series of 'directives' that participants receive several times a year, which they then write about in a style characterized as combining a kind of autobiography and amateur sociology (Sheridan, Street, and Bloome). There have been many directives concerning literacy in society over the years, and as a part of RABiT, in 2017, a new directive was sent out that spe- 
cifically concerned reading aloud in everyday life. This directive and responses to it are included in chapter four.

In chapter five Duncan discusses the recordings of interviews and examples of reading aloud. One point to note here regarding these is that, similarly to how participant responses to the MOA directive would become part of the UK Mass Observation Archive, so recordings for RABiT are integrated into the British Library Sound Archive-ultimately forming part of broader and ongoing social history projects made available to the public. Personally, here, reading about the researcher going off to the Shetland Islands in Scotland to record people's voices for national library archives reminded me of the work of Alan Lomax and others in the fields of folklore studies and ethnomusicology, or perhaps closer, linguistic anthropology and sociolinguistics (see, for example, Richard Bauman) - but I had not encountered this kind of archival recording directly before in the field of literacy studies.

Next, from chapters six through twelve, the book empirically and theoretically investigates six main themes that emerged through the questionnaires, MOA directive, and interviewing data. As the first of these, chapter six is entitled "Family, Friends, and Lovers" and it focusses on reading aloud as a way of being with others. In doing so, it discusses ideas of community, domesticity, and intimacy, as well as how oral reading practices serve to mediate between "inner and outer worlds, personal and political worlds, familial and global worlds" (Duncan 83). Beyond questions of power associated with social groups and respective contexts, this chapter also highlights different ways that participating in reading aloud practices can join people together physically and/or affectively, and how in particular, both the voice and shared texts can enact love.

Chapter seven discusses working life. Reading aloud is shown here as ubiquitous "in larger and smaller, more and less obvious, ways across our working lives and lives as citizens" (115). As in other studies of literacy practices we get the sense here of how reading aloud practices hold workplaces together, as it were, through the performing, mediating, and disseminating of social roles and relations. The chapter discusses ten specific areas of work in closer detail: editors, writers, actors, broadcasters, religious figures, magistrates, judges, registrars, librarians, and teachers. Across all examples, reading aloud practices are "slightly different in each case, as purposes, priorities and contexts vary, as do power relationships and the ways in which written documents are used" (Duncan 115). This point links to different subjectivities, as well as, ultimately, "the systems of organisation, law or administration that we deal with as citizens" (Duncan 114). Relating to the latter, the chapter ends by discussing two areas of social life where people are seen, first, being pushed away by, and second, pushing back against, systems of governance. The two examples Duncan gives concern the role of reading aloud and related literacy practices, in the prison system, and in protest movements.

Chapter eight concerns religion. In discussing multiple religions and related forms of oral reading, the chapter revolves around what it refers to as five areas of difference and three areas of commonalty. The former includes different religions, different systems of belief, formations (of activities), physicality (bodies, objects, and 
spaces), texts, and languages. In the latter, commonality is discussed through memory, meditation, and meaning. In contrast with reductionist understandings of rote learning, Duncan emphasizes here how "across different religious traditions memorisation and recitation are associated with forms of meditation, creativity and the accessing of deeper meanings or understandings" (127). One concept-from Myra Barrs-that follows is that of "reading aloud, and/or hearing, sacred texts" becoming "a meeting place for worshippers past, present and future" (127). Multiple roles of the body, the voice, and the ear are discussed in turn as are what Tuuli Lukkala calls the personal-cultural soundscapes of religious spaces-or "everything a person can hear in a given place and time", whereby "what people perceive and pay attention to as well as the meanings people give to different sounds var[ies]" (Duncan 122).

The next topic in chapter nine is literary life, and aspects of production, performance, and experience framed as being literary. One main argument of this chapter is that every human being can be thought of as having a literary life, once, that is, high-cultural notions of literature are deconstructed, and emphasis is placed on the central role that stories occupy in people's lives. Duncan summarizes that a literary life is "a creative and story-alive life, awake to the experiences of others, whether reading, writing, singing, hearing, watching or imagining them" (136). Notions of sound are central to this chapter once again, drawing on ideas including the auditory imagination from T.S. Eliot as the particular (and primal) place of the ear and voice, and of sound and rhythm, in experiences and meaning making through texts as poetic. We also get the profound reminder that when we take up texts through oral reading, such as through song, poetry, and drama, we lend the text, not only our conscious engagement, but also our bodies and our breath or life force. Drawing on dramaturgical theory, Duncan discusses role playing from Dorothy Heathcote throughout the chapter, both generally as a site in which creativity and coping strategies can develop, and more specifically, in terms of shifting roles in production processes, and a kind of oral-aural reflexivity, such as where writers, shift from, for example, writing, to reading and listening, to judging, and editing work.

Chapter ten focusses on solitude and reading aloud alone. The chapter opens by asking the question: do people actually read aloud alone, and if so, what and why? Besides issues relating to who is not there to listen; cognition, affect, and the voice itself are considered. Duncan makes the point that oral reading is most commonly thought of in communicational terms, as between people, but in this case, "if we consider someone reading aloud as she sits, completely alone, and writes a story, checks an index or enjoys ... poetry, whatever her voice is doing, it is not serving or communicating with others" (152). The chapter then develops its argument around two overarching categorizations: thinking and feeling. In relation to the former, examples of oral reading are shown to form part of "individual thinking work" such as: "focusing or concentrating; memorising or learning; and understanding, picking or interpreting" (Duncan 154). The second overarching category of feeling interconnects overlapping notions of sensoriality and identity. People are shown reading alone in this case for reasons relating to personal and group needs and identities; spirituality and religion; 
enjoyment and pleasure; as well as to invoke feelings of comfort and company; and, for some, to establish a sense of being present in the world.

Chapter eleven, lastly, discusses education and oral reading. Duncan reminds readers in this chapter that the main purpose of the book and $\mathrm{RABiT}$ research was not a directly pedagogical one. Nevertheless, owing to education being a common frame of reference for participants, this did become one of the life domains to which they referred. Chapter eleven consequently describes reading aloud within planned educational settings - early reading, reading development, and language teaching. Beyond these areas, however, Duncan highlights that, through the RABiT data, in fact, the majority of examples of reading aloud in education mentioned by participants actually referred to subjects not specifically concerning language or literacy (e.g. biology, technology, math). Duncan discusses more generalized uses of oral reading, where, for instance, "participants speak of reading aloud to give instructions and share information. . . to bring learners together in a shared listening activity, to focus on a text being studied. . . to share and celebrate students' work, or to quieten or raise the mood" (166). This list thus becomes another example of the broader ethnographic observation throughout the book, where oral reading practices weave together broader social practices and contexts, in this case, principally, pedagogical, and educational ones. What chapter eleven, and the book on the whole suggest, then, and successfully so, is the need for an expanded sense of "what is understood by [oral] 'reading' in the first place" - as part of people's daily lives-and with this then supporting an improved understanding of how the doing, learning, and teaching of oral reading takes place (Duncan 176).

\section{Works Cited}

Barrs, Myra. “The reader in the Writer." Reading, vol. 34, no. 2, 2000, pp. 54-60.

Bauman, Richard, ed. Folklore, Cultural Performances, and Popular Entertainments: A Communications-Centered Handbook. Oxford University Press, 1992.

Duncan, Sam. Oral Literacies: When Adults Read Aloud. Routledge, 2020.

Eliot, T.S. The Uses of Poetry and the Use of Criticism. Faber and Faber, 1964.

Heathcote, Dorothy. "How Does Drama Serve Thinking, Talking and Writing?" Elementary English, vol. 47, no. 8, 1970, pp. 1077-81.

Lukkala, Tuuli. "The Soundscape of Orthodox Christian Worship." Music and the Sacred, vol. 41, no. 2, 2019, pp. 286-92.

Sheridan, Dorothy, Street, Brian V., and Bloome, David. Writing Ourselves: Mass-Observation and Literacy Practices. Hampton Press, 2000. 